\title{
Human Health and Sustainability Depend on Diverse Ecological Environments- Monitoring of Flora and Flowering Phenology in Huajiang Wildduck Natural Park
}

\author{
Yibin Fan ${ }^{1 *}$, Mingsheng $\mathrm{Liu}^{2}$ and Yuyen Yung ${ }^{2}$ \\ ${ }^{1}$ Associate researcher of Liokuei Research, Taiwan Forestry Research Institute, ROC, Former Chairman of Huajiang Wetland \\ Guardian Alliance, Taiwan \\ ${ }^{2}$ Chief of ecological monitoring Botanical Division, Huajiang Wetland Guardian Alliance, ROC, Taiwan
}

*Corresponding author: Yibin Fan, Associate researcher of Liokuei Research, Taiwan Forestry Research Institute, ROC, Former

Chairman of Huajiang Wetland Guardian Alliance, Taiwan

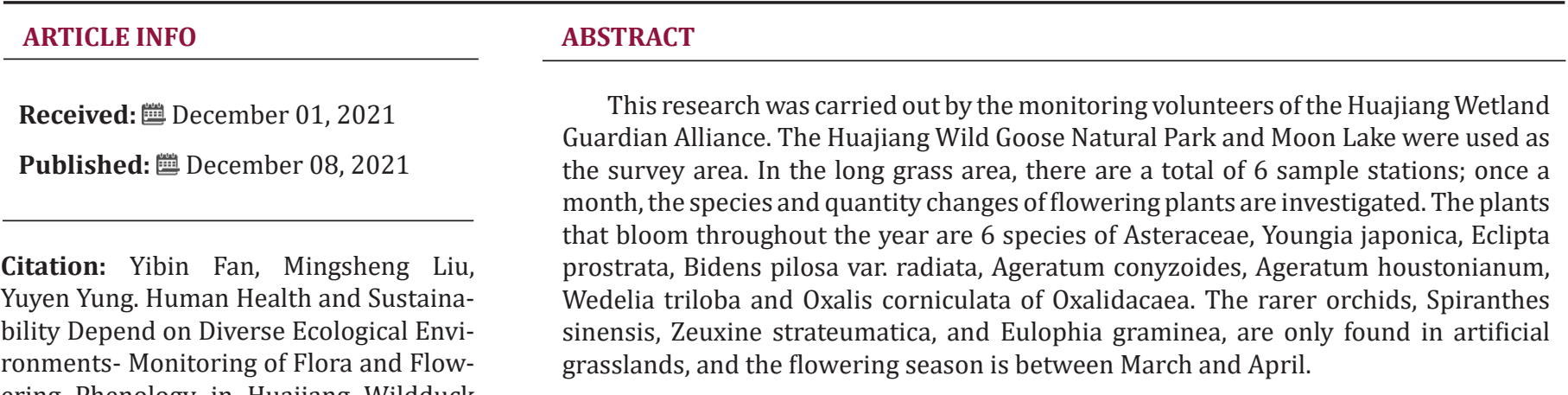
ering Phenology in Huajiang Wildduck Natural Park. Biomed J Sci \& Tech Res 40(3)-2021. BJSTR. MS.ID.006452.

Keywords: Huajiang Wildduck Natural Park; Flora; Flowering Phenology; Ecological Monitoring; Monitoring Volunteers

\section{Introduction}

With the expansion of cities, the rise of power plants, and the improvement of living standards, many people can sit in well-airconditioned and elegantly decorated restaurants and eat delicious food made with ingredients from afar, but there is another group of people in the world facing poverty, hunger and disease. Their humble homes cannot resist natural disasters, and they do not have good job opportunities. They can only cultivate barren or contaminated farmland, or overwork in dangerous mines and factories. According to the United Nations' Sustainable Development Goals (SDGs), 15 items are terrestrial ecology, emphasizing the importance of biodiversity. Human health and sustainability depend on diverse ecological environments Huajiang Wild Goose and Duck Nature Park" is located under the Huajiang Bridge in Wanhua District in the southwestern corner of Taipei City. The total area is about 28 hectares. It belongs to the category of Dahan-Xindian Wetland. In 1991, the Taipei City Industrial Development Bureau set up interpretive facilities in this area and set up the "Goose Duck Park" to introduce conservation concepts into the park's management [14].

It was officially renamed "Huajiang Wild Goose Natural Park" in 1996. The Huajiang Wetland Conservation Alliance started its environmental monitoring activities in 2007 , so that more people 
who love ecology and value the environment will come to participate in wetland ecological monitoring and protection activities and build knowledge of the local environment through the process of participation. Improve emotional recognition of Huajiang Wetland.

\section{Research Location}

With Huajiang Bridge as the boundary, it is divided into north and south regions, and then divided into artificial grassland, short grass region, and long grass region according to the difference of the flora of the north and south regions, for a total of 6 sample stations. Artificial grassland: There are often human activities and regular artificial weeding. The vegetation is more complex, with low herb plants such as gooseberry, water centipede, and nightshade. The Moon Pond in Huajiang Wild Goose Natural Park has been completed since December 2012. The ecological island of the pond has been deserted. The area has been investigated and monitored without human intervention.

\section{Methods}

Before 2011, the survey method of the flora group was to set a crossing line and select a survey plot of $5 \mathrm{~m} \times 5 \mathrm{~m}$ on the sample line. However, this kind of survey method is very hot in the unshaded wetland. After one or two times, no volunteers are willing to come. In response to this problem, the first author modified the plant sample area survey into plant phenology monitoring. After the operation, I found that the phenological survey is still too complicated for volunteers, so I had to simplify it and only focus on the species that bloom every month. The survey method is to survey once a month, dividing the Huajiang Bridge into two areas in the north and south, and then dividing it into artificial grassland, short grass area, and long grass area according to the plant phase. The crossing line through these three areas is used as the survey scope. Beginning in May of 2005, the species and quantity of plants will be recorded until 2019.From 2011 to the end of 2019, it will be carried out once a month by crossing the line and divided into 6 sample areas to investigate the flowering species of flowering plants.

\section{Results}

From 2011 to the end of 2019, Huajiang Wild Goose Nature Park has recorded a total of 262 species of vascular plants in 57 families, of which 44 species of Poaceae are the most, followed by 36 species of Asteraceae. Varieties of vascular plants in Huajiang Wild Goose Nature Park have changed since 2012.In the year, there were 199 species in 45 families. In the second year, it suddenly increased to 241 species in 46 families, an increase of 42 species in 1 family, and then by the end of 2019 , it increased to 262 species in 57 families, and 21 species in 11 families (Table 1). The results also show that plants bloom every month. There are more plants in the southern area of Huajiang Bridge than in the northern area. The artificial grassland is the most, and the human disturbance is the largest. On the contrary, the species is taller than the short grass and long grass areas with less human disturbance (Figure 1).

Table 1: Vascular plant diversity changes in Huajiang Wild Goose Natural Park.

\begin{tabular}{|c|c|c|c|}
\hline Families/species & $\mathbf{2 0 1 2}$ & $\mathbf{2 0 1 3}$ & $\mathbf{2 0 1 9}$ \\
\hline Poaceae & 28 & 42 & 44 \\
\hline Asteraceae & 28 & 34 & 36 \\
\hline Cyperaceae & 13 & 18 & 19 \\
\hline Polygonaceae & 12 & 12 & 13 \\
\hline Scrophulariaceae & 11 & 13 & 13 \\
\hline Euphorbiaceae & 9 & 12 & 13 \\
\hline Fabaceae & 9 & 10 & 11 \\
\hline Other families & 98 & 100 & 113 \\
\hline Total & 199 & 241 & 262 \\
(45 families) & (46 families) & (57 families) \\
\hline
\end{tabular}

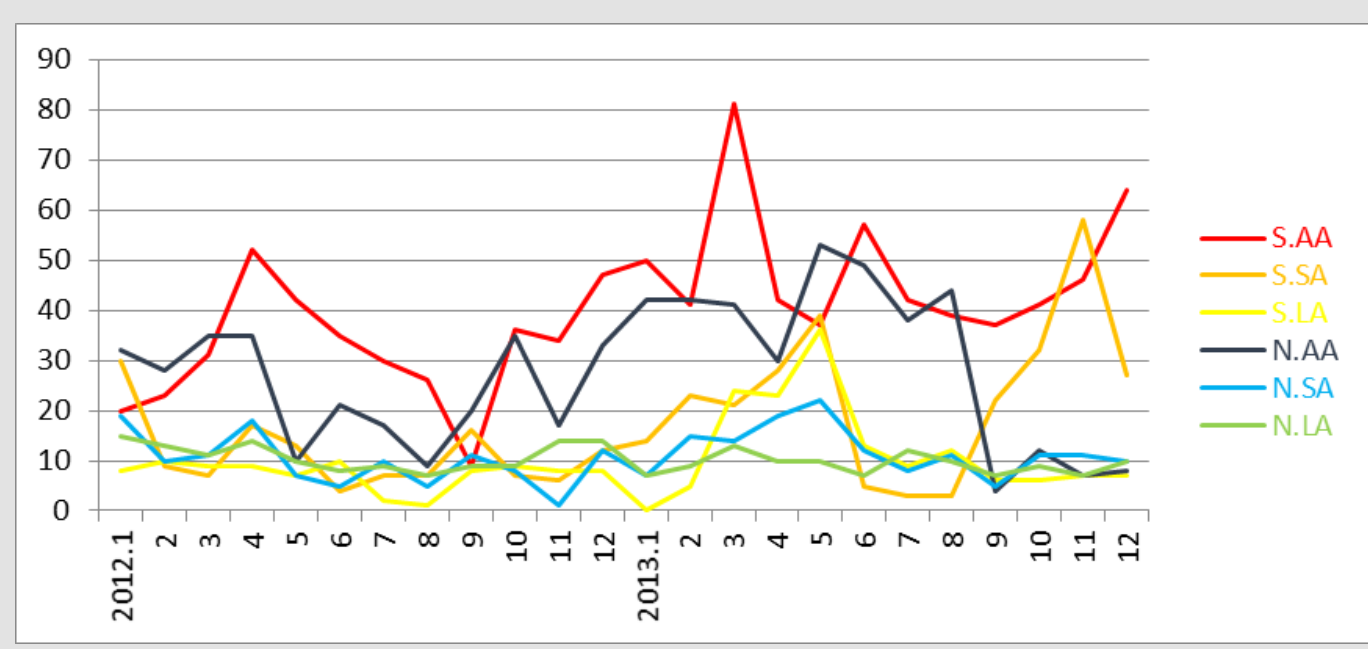

Figure 1: Monthly change of flowering plants at 6 plots in Huaji ang Wild Goose Natural Park. 
The rarer orchids, Spiranthes sinensis, Zeuxine strateumatica, and Eulophia graminea, are only found in artificial grasslands, and the flowering season is between March and April. The flowering species are unevenly distributed in the seasons. From 2012 to 2019, the most flowering seasons are 5 years in May, 2 years in April, and 1 year in March and June (Figure 2). The plants that bloom throughout the year are 6 species of Asteraceae, Youngia japonica,
Eclipta prostrata, Bidens pilosa var. radiata, Ageratum conyzoides, Ageratum houstonianum, Wedelia triloba and Oxalis corniculata of Oxalidacaea. Around Moonpond, there are regular weeding. The most species month in 2014 was June, with 22 families and 77 species. The most frequent month in 2016 was April, with 23 families and 89 species. Among them, it was recorded in April 2020 (Figures 3-5).

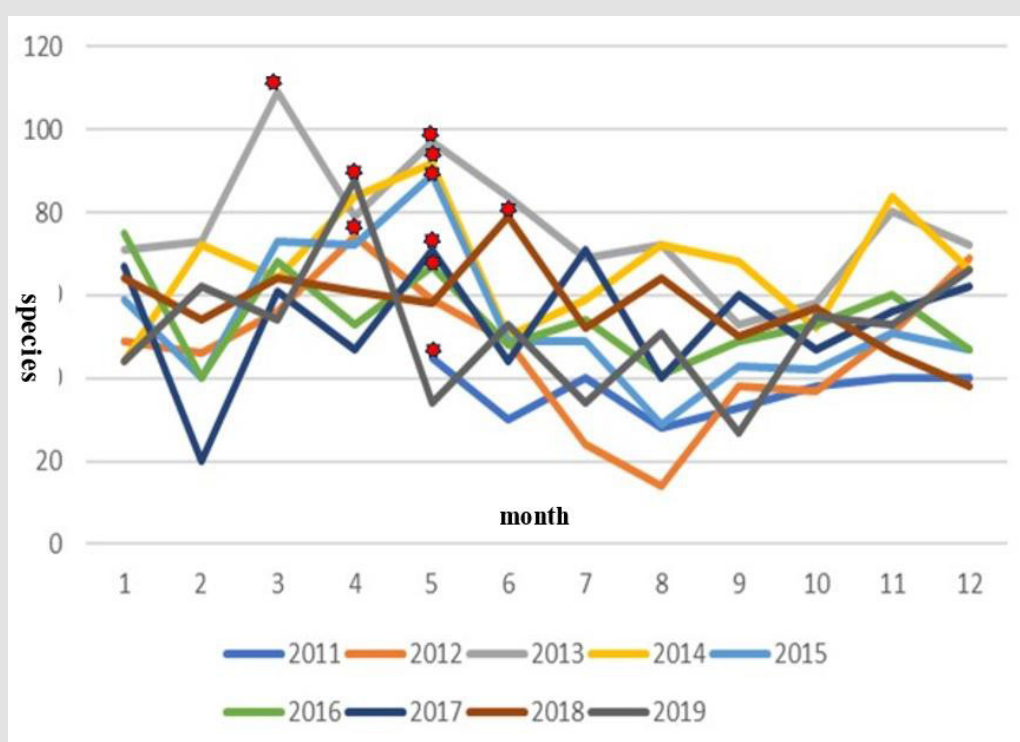

Figure 2: 2011-2019 The most flowering month in Huajiang Wild Goose Natural Park ( )

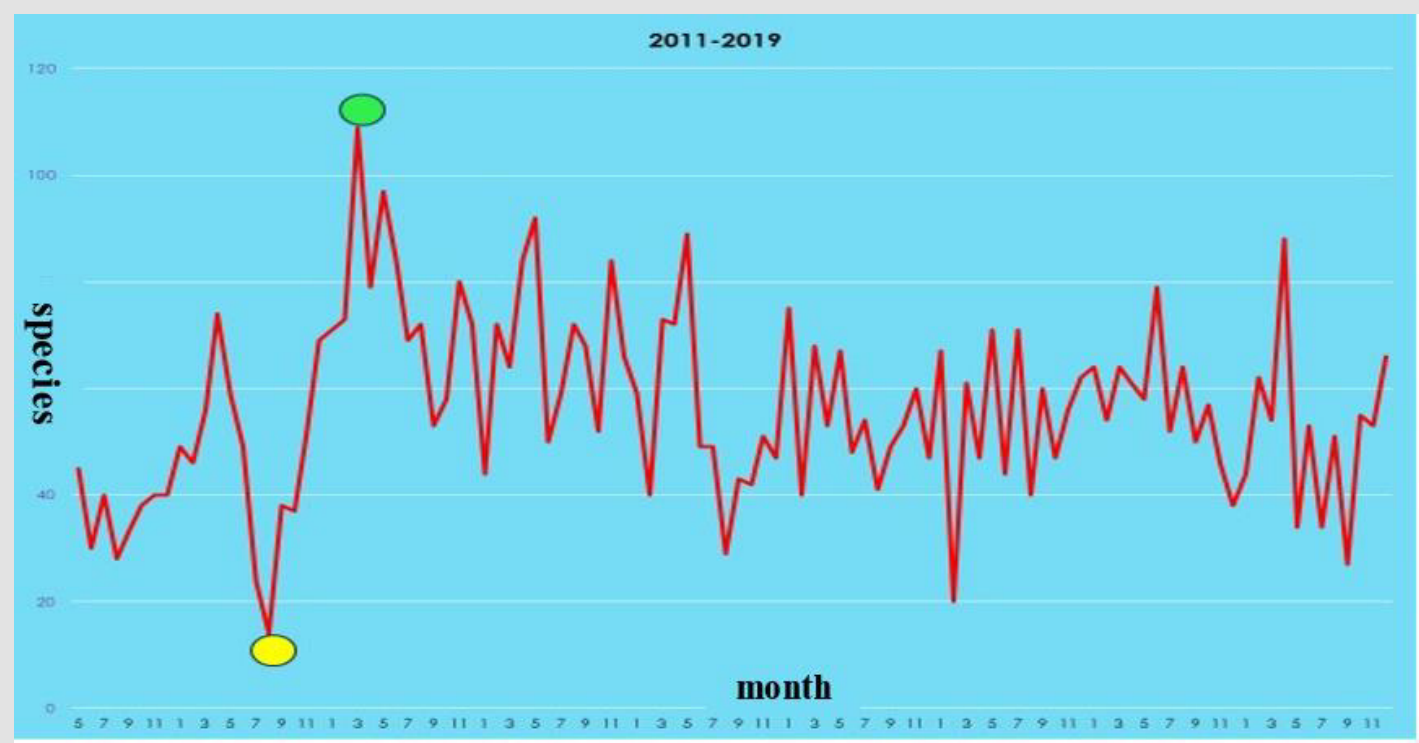

Figure 3: 2011-2019 Monthly changes of flowering phenology in Huajiang Wild Goose Natural Park(oHaikui typhoon) 


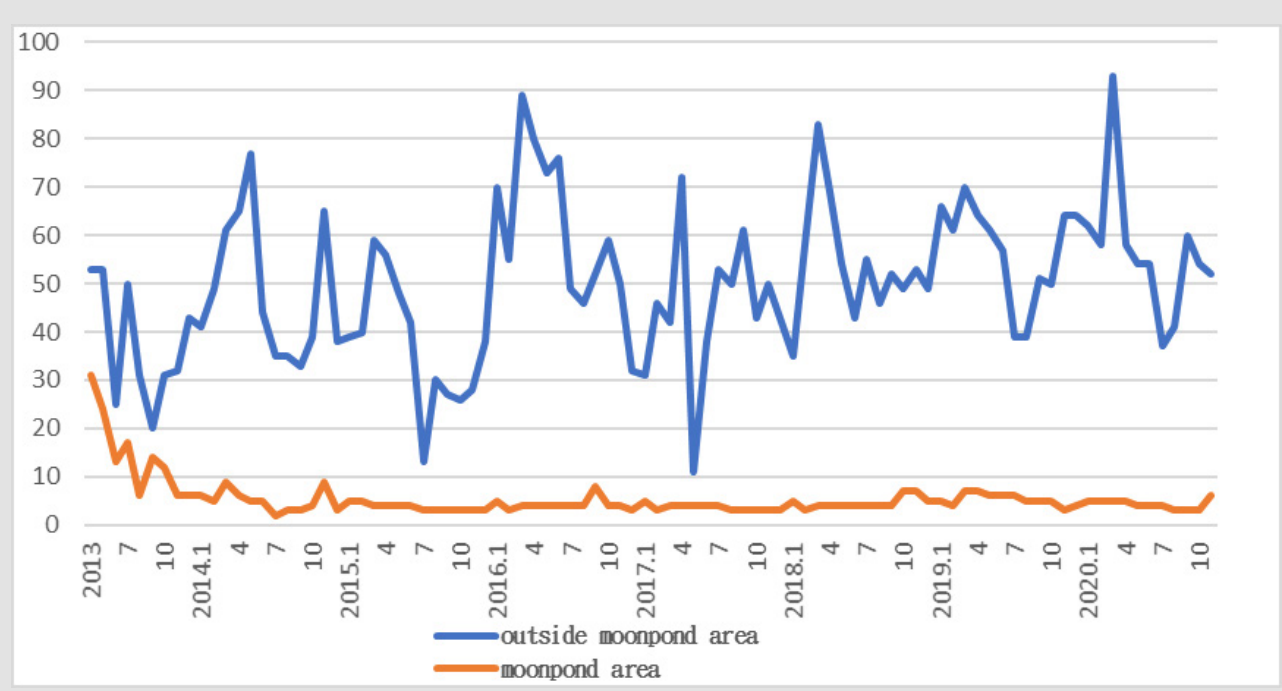

Figure 4: Monthly Variations of Flowering Plants in Moon pond of Huajiang Wild Goose Natural Park.

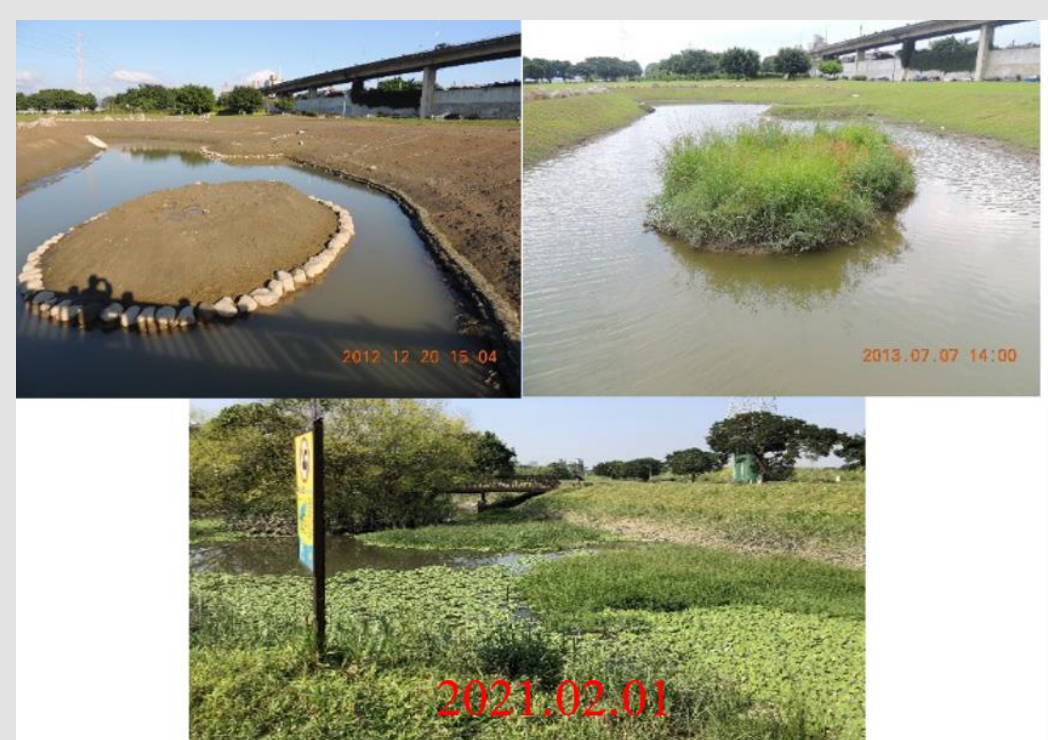

Figure 5: Environmental changes of Moonpond.

\section{Discussion}

According to the survey results, March to April and November to December are the months with the most flowering plants. And the rarer orchids, Spiranthes sinensis, Zeuxine strateumatica, and Eulophia graminea, are only found in artificial grasslands, and the flowering season is between March and April. The competent authority should consider avoiding weeding during the months when flowering plants reproduce the most, moreover to maintain the flowering and reproduction of plants and protect the rarer plants from extinction. From 2012 to 2019, the typhoon had the greatest impact on the Huajiang Wild Goose Natural Park was the moderate Haikui typhoon on August 6, 2012, which caused the
Huajiang Wild Goose Natural Park to be flooded to a depth of 3m, and the flooding time lasted than one week. (Figure 3) And there is nearly $1 \mathrm{~m}$ high silt cover, the impact on flowering plants is only when the number of species decreased significantly in the month, only 14 species, and then the species gradually increased. By March 2013, 109 species of plants bloomed and reached the highest peak, which is the most month.

This phenomenon is likely to be caused by the Haikui typhoon that brought many plant seeds from upstream in August 2012. The seeds gradually germinated, grew and bloomed. They reached the highest point in March 2013 and then gradually declined. The possible reason is adaptability. However, since only the Haikui 
typhoon has directly affected the Huajiang Wild Goose Natural Park in the past 9 years, whether this phenomenon is the norm under the influence of typhoons remains to be verified by the next typhoon directly affected. The monitoring results of the Huajiang Wild Goose Natural Park can provide the evidence of climate change. In the future, investigations of rare plants, such as the ethnic changes of orchids, should be strengthened. Under the influence of this increasingly violent climate change, it is imperative to create a biodiversity environment. Therefore, monitoring must continue. However, in addition to the enthusiastic support and participation of volunteers, monitoring also requires government support and financial subsidies.

\section{Acknowledgement}

This research monitoring case is grateful to Professor Li Zaiming of Cultural University, Dr. Chen Qidong, National Taiwan University Life Sciences Institute, Chen Jianwen, and Mr. Zhong Mingzhe of the Forestry Laboratory for their guidance and plant identification, and also to a group of people who are not fame and fortune, not afraid of the cold, the sun and the rain. plant group partners of Wetland Huajiang Wetland Guardian Alliance: Liu Jixiong, Huang Bingrong, Huang Jinyun, Chen Yanming, Zhang Yiting, Zheng Yingzhi, Huang Xincong and others have been able to complete the data that have been painstakingly recorded.

\section{Declarations}

All manuscripts must contain the following sections under the heading 'Declarations':

\section{ISSN: 2574-1241}

DOI: $10.26717 /$ BJSTR.2021.40.006452

Yibin Fan. Biomed J Sci \& Tech Res

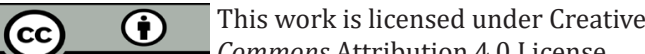
Commons Attribution 4.0 License

Submission Link: https://biomedres.us/submit-manuscript.php
- Ethics approval and consent to participate: Not applicable

- Consent for publication: Not applicable

- Availability of data and materials: Not applicable

- Competing interests: Not applicable

- Funding: Not applicable

- Authors' contributions: Data collection, literature review, manuscript writing

- Acknowledgement: Not applicable.

\section{References}

1. Weida Fang, Ho Yixian, Fang Weihong (2007) Research on habitat changes in Huajiang Bridge Wild Goose Reserve. National Tainan University, Tainan.

2. Wu (2008) Community Participatory Management of Wetlands-Taking Taipei City Wild Goose Natural Park as an example. Master's Thesis, Institute of Natural Resources and Environmental Management, National Taipei University.

3. Huilian Xie, Zhang Wenxian, Chen Zhangbo (2008) Study on the wetland restoration and management of Danshui River Dahan Xindian. The first Asian Wetland Conference. National Taiwan University Hospital International Conference Center, Taipei City.

4. Daojie Lu (2009) Relevant research report on Taipei Wild Goose Reserve. Reserve in Taipei City.

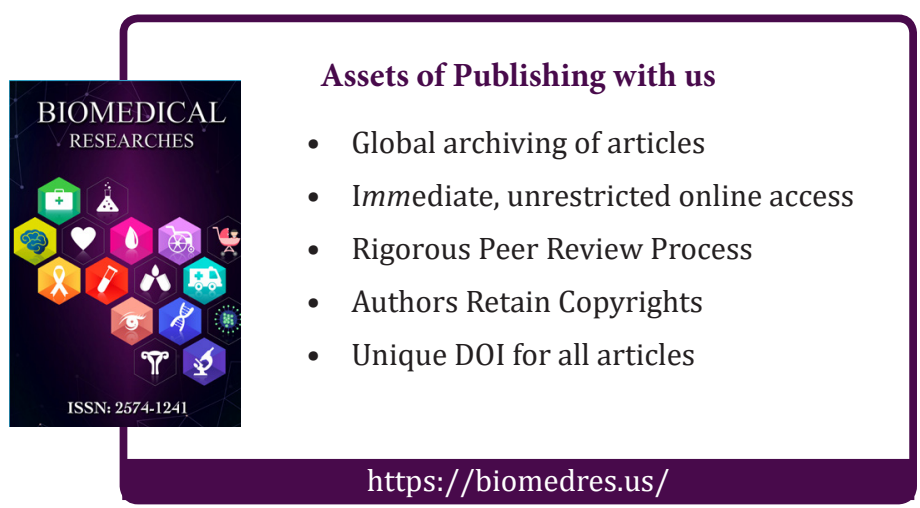

